\title{
Solute Carrier Family 6 Member 12 Gene Polymorphisms in Japanese Patients with Aspirin-Exacerbated Respiratory Disease
}

\author{
Motohiro Kurosawa ${ }^{1,2^{*}}$, Yujin Sutoh ${ }^{3}$, Tatsuo Yukawa ${ }^{4}$, Soichiro Hozawa ${ }^{5}$ and Eijin Sutoh ${ }^{1}$ \\ ${ }^{1}$ Department of Allergy and Respiratory Medicine, Sutoh Hospital, Annaka-shi, Gunma, Japan \\ ${ }^{2}$ Gunma Institute for Allergy and Asthma, Gunma, Japan \\ ${ }^{3}$ Department of Surgery, National Hospital Organization Takasaki General Medical Center, Takasaki, Gunma, Japan \\ ${ }^{4}$ Yukawa Clinic of Internal Medicine, Tochigi, Japan \\ ${ }^{5}$ Hiroshima Allergy and Respiratory Clinic, Hiroshima, Japan
}

*Corresponding author: Kurosawa M, Department of Allergy and Respiratory Medicine, Sutoh Hospital, 3532-5 Annaka, Annaka-shi, Gunma 379-0116, Japan, Tel: +81-27-382-3131, Fax: +81-27-382-6568; E-mail: motohiro@kl.wind.ne.jp

Received date: August 04, 2015; Accepted date: August 31, 2015; Published date: September 07, 2015

Copyright: (c) 2015 Kurosawa M, et al. This is an open-access article distributed under the terms of the Creative Commons Attribution License, which permits unrestricted use, distribution, and reproduction in any medium, provided the original author and source are credited.

\begin{abstract}
Background: Betaine/gamma-aminobutyric acid (GABA) signaling pathway in the airway epithelium has been revealed to play a critical role in bronchial asthma. To elucidate any genetic influence of the GABAergic in aspirinexacerbated respiratory disease (AERD), we investigated the association of solute carrier family 6 (neurotransmitter transporter, betaine/GABA) member 12 (SLC6A12) gene in Japanese patients with AERD.
\end{abstract}

Methods: DNA specimens were obtained from 103 AERD patients, 300 patients with aspirin-tolerant asthma (ATA) and 100 normal controls. Allelic discrimination assay for two single nucleotides polymorphisms in SLC6A12 gene (rs499368 and rs557881) was carried out.

Results: The minor allele frequencies in SLC6A12 intron 2 A>T genotype (rs49936) were higher in AERD patients than in normal controls, and that in SLC6A12 exon $4 \mathrm{~T}>\mathrm{C}$ genotype (rs557881) were higher in AERD patients than in ATA patients and normal controls. The frequencies of the combined TC/CC genotype group of SLC6A12 exon 4 T >C were higher than those of the TT genotype in AERD patients compared with those in ATA patients $(P=0.021$; odds ratio, $1.724 ; 95 \%$ confidence interval, 1.087-2.732). In male patients with AERD, frequencies of the TC/CC genotype group were higher than those of the TT genotype compared with male patients with ATA ( $P=0.010$; odds ratio, 3.177; 95\% confidence interval, 1.311-7.699). Forced expiratory volume in one second (percentage predicted) in AERD patients with the TC/CC genotype group of the SLC6A12 exon 4 T>C gene was lower than that in the patients with the TT genotype $(P=0.039)$.

Conclusion: This is the first Japanese study to investigate the SLC6A12 intron 2 A $>$ T and SLC6A12 exon 4 T>C genotype polymorphisms in patients with AERD. Our findings suggest that the association between SLC6A12 intron $2 \mathrm{~A}>\mathrm{T}$ and exon $4 \mathrm{~T}>\mathrm{C}$ gene sequence variations might be implicated in the development of AERD in a Japanese population.

Keywords: Solute carrier family 6 member 12; SLC6A12; Gene polymorphism; Aspirin-exacerbated respiratory disease; AERD; Aspirin-tolerant asthma

\section{Introduction}

Aspirin-exacerbated respiratory disease (AERD), so-called aspirinintolerant asthma, is a clinical syndrome characterized by severe asthmatic attacks after ingestion of aspirin and/or nonsteroidal antiinflammatory drugs (NSAIDs) [1]. AERD is known to be associated with less atopic tendency, persistent eosinophilic infiltration in the airway mucosa, and a more severe clinical course [1]. The inhibitory action of aspirin and NSAID on cyclooxygenase activity may cause diversion to the 5-lipoxygenase pathway, leading to the overproduction of cysteinyl leukotrienes (LTs) [1]. A general consensus exists that increased levels of cysteinyl LTs are key inflammatory mediators in AERD. However, a study of Japanese asthmatic patients demonstrated that prostaglandin D2 was overproduced during aspirin-intolerant bronchoconstriction, and the urinary concentrations of LTE4 and metabolites of prostaglandin D2 correlatively increased during the reaction [2].

As aspirin intolerance is found only in a specific population, genetic predisposition is considered a crucial determinant for the development of AERD. Candidate genes have been concentrated on LT-related genes. Namely, LTC4 synthase promoter polymorphism was reported to be associated with AERD $[3,4]$. Also, the genetic polymorphisms of 5-lipoxygenase promoter [5] and cysteinyl LT receptor 1 promoter [6] were shown to influence the susceptibility to AERD as risk factors. However, conflicting results have been reported [7,8], and other genetic determinants remain to be identified. We have reported some new genetic aspects in Japanese patients with AERD [9-14].

It has been revealed that betaine/gamma-aminobutyric acid (GABA) signaling pathway in the airway epithelium plays a critical role in asthma development through its ability to enhance mucus 
production [15]. Previous studies have indicated that during the development of allergen-induced airway responses, GABAergic system in the airway epithelial cell acts in autocrine and paracrine fashion to enhance mucus hyper-secretion from airway epithelial cells resulting to airway obstruction $[16,17]$.

Solute carrier family 6 (neurotransmitter transporter, betaine/ GABA) member 12 (SLC6A12) gene, also referred to as sodium and chloride-dependent betaine/GABA transporter-1, is widely expressed in the proximal tubules of the kidney and cells of the central nervous system $[18,19]$. In the renal medulla, elevated transcription of SLC6A12 causes the cells to accumulate compatible osmolytes to high concentrations, resulting in a balanced extracellular hypertonicity [18], thus, reducing hypertonicity stress. The basolateral distribution of SLC6A12 is suggestive of either a post-synaptic site of action or alternatively, that this transporter serves to clear GABA from the cerebrospinal fluid/extracellular fluid in non-synaptic region [20]. On the other hand, it has been reported that airway remodeling and the correlation of the extraneuronal GABAergic system might be implicated in AERD [21].

To our knowledge, only one report has investigated the association between SLC6A12 gene polymorphisms and AERD. Namely, Pasaje et al. [22] reported that eight polymorphisms, including two single nucleotide polymorphisms (SNPs) in the coding region in SLC6A12 gene, exon 4 and 17 (rs557881 and rs2075228) and six SNPs in the non-coding region in SLC6A12 gene, intron 1, 2, 7 and 14 (rs3759373, rs 499368, rs216244, 216242, rs2284330, and rs2284329) were successfully genotyped in their study, and then indicated that two SNPs (rs499368 and rs557881) in SLC6A12 gene were significantly associated with AERD in a Korean population. Therefore, taking all into account, we sought to partly replicate the association previously described between SLC6A12 gene and AERD patients among Korean population, and based on their results [22], only two SNPs in SLC6A12 gene, intron $2 \mathrm{~A}>\mathrm{T}$ in the non-coding region and exon $4 \mathrm{~T}>\mathrm{C}$ in the coding region (rs499368 and rs557881) were tested in Japanese patients with AERD.

\section{Materials and Methods}

\section{Subject}

This study was approved by the institutional review board at each clinical site in Japan, and was conducted in conformance with the ethical principles on the Declaration of Helsinki, Good Clinical Practices, and applicable local regulations. Written informed consent was obtained from each patient before study procedures were initiated.

All subjects were nonsmoking Japanese and were recruited from the outpatient clinic of Sutoh Hospital, Yukawa Clinic of Internal Medicine, and Hiroshima Allergy and Respiratory Clinic, Japan. Smoking habit was ascertained by means of a questionnaire. Characteristics of the study population are shown in Table 1.

Diagnosis of bronchial asthma was confirmed using the Global Initiative for Asthma guidelines [23]. All patients showed clinical symptoms that met the criteria for asthma, such as cough, wheeze and shortness of breath, and they were diagnosed by experienced pulmonologists. Forced expiratory volume in one second (FEV1) was measured with a spirometer, and airway reversibility was defined as a $>12 \%$ and $>200 \mathrm{~mL}$ increase in volume in the first second of forced expiration from baseline after inhalation of short-acting $\beta 2$-adrenergic bronchodilators. The diagnosis of AERD was made on the basis of a positive result on lysine-aspirin challenge test [4]. Ideally, everyone in the study should have the challenge test; however the provocation test could not be applied to the one-fourth of the subjects because they didn't give written informed consent. Although placebo-controlled oral challenge tests are considered the best for the diagnosis of AERD, the suspected drugs were not applied to the subjects in this study because of patients' refusal and our safety policy of inpatient provocations only [24]. So, their diagnosis was made by an apparent history of more than one self-reported episode of bronchial response to aspirin or NSAID ingestion by experienced Japanese pulmonologists. Aspirin-tolerant asthma (ATA) was defined as bronchial asthma with no history of NSAID-induced asthma attack. Non-smoking subjects with no history of bronchial asthma or other respiratory symptoms were selected from healthy volunteers who visited our clinic for annual routine physical examinations, and comprised normal controls. The serum levels of total IgE were measured by the CAP system (Phadia, Uppsala, Sweden). The total eosinophil count was measured in peripheral blood using a flow cytometer (Coulter Maxm; Beckman-Coulter Inc, Fullerton, CA, USA).

\section{Genotyping of SLC6A12 gene polymorphism}

DNA in the specimens obtained by rubbing buccal mucosa by a cotton swab was extracted by using QIAamp 96 DNA blood kits (Qiagen, Hilden, Germany). The target DNA sequence of SLC6A12 intron 2 A $>\mathrm{T}$ was amplified using a set of primers (forward: 5'TGCTGACTCAGATGTCAACCTG-3', reverse: 5' ATGAGGCACCCT-GAGAAATG-3'). The target DNA sequence of SLC6A12 exon $4 \mathrm{~T}>\mathrm{C}$ was amplified using a set of primers (forward: 5'-TCTTCCCACCAGGCTTTG-3', reverse: 5'-TCCAACTTCTCTCССТССТC-3'). Allelic discrimination assay for two SNPs relating to the expressions of SLC6A12 intron $2 \mathrm{~A}>\mathrm{T}$ and SLC6A12 exon 4 T>C (rs499368 and rs557881, respectively) was carried out by using previously described SNPs detective system, sequence-specific thermal-elution chromatography [9-14]. All subjects and investigators remained unaware of the genotype until the final analysis.

\section{Statistical analysis}

Data are presented as means \pm SD or numbers (\%) of observations, unless stated otherwise. Differences in the mean value of the phenotypic characteristics within the groups were compared using either ANOVA test or t-test, and qualitative data were compared by the Chi-square test. Allele frequencies were estimated by gene counting method. Significant departures of genotype frequency from the HardyWeinberg equilibrium at each SNP were tested by the Chi-square analysis. Differences in the minor allele frequencies of SLC6A12 intron $2 \mathrm{~A}>\mathrm{T}$ and SLC6A12 exon $4 \mathrm{~T}>\mathrm{C}$ (rs499368 and rs557881) in AERD patients were compared with ATA patients and normal controls by means of the Chi-square test. Logistic regression analysis was used to estimate odds ratio (OR) and 95\% confidence interval (CI). Each gene polymorphism related to the asthma phenotype was examined by multivariable logistic regression models with adjustment for covariates, namely with the asthma phenotype as dependent variable and independent variables including age (continuous value), gender (male $=0$, female $=1$ ), two alternatives genotype models that were homozygous AA genotype and combined heterozygous AT genotype and homozygous TT genotype group in SLC6A12 intron $2 \mathrm{~A}>\mathrm{T}$ (rs499368), and homozygous TT genotype and combined heterozygous TC genotype and homozygous CC genotype group in SLC6A12 exon 4 
T $>C$ (rs557881). In addition, subgroup analyses with gender of the multivariable logistic regression analysis were performed in each gene. Statistical analyses were undertaken using SPSS for Windows version 17 (SPSS Inc, Chicago, IL). Our study has to be considered exploratory in nature. Therefore, no correction for multiple testing was carried out. P-values of $<0.05$ were considered to be significant.

\section{Results}

The clinical and hematological characteristics of the study subjects are summarized in Table 1. All patients were in a stable clinical condition, and there was no significant difference between AERD patients and ATA patients in terms of age, gender and FEV1 (\% predicted). The mean value of hematological characteristics analyzed by the Welch's t-test indicated that the levels of total serum IgE in AERD patients were significantly lower than those in ATA patients $(\mathrm{P}<0.01)$, and the total count of peripheral blood eosinophils in AERD patients was significantly higher than that in ATA patients $(\mathrm{P}<0.01)$.

\begin{tabular}{|l|l|l|l|}
\hline & AERD & ATA & NC \\
\hline Number of subjects & 103 & 300 & 100 \\
\hline Age (years) & $51.4 \pm 13.4$ & $49.8 \pm 15.9$ & $47.1 \pm 13.6$ \\
\hline Gender (male) & $27(26.2 \%)$ & $107(35.7 \%)$ & $34(34.0 \%)$ \\
\hline FEV1 (\% predicted) & $73.7 \pm 11.3$ & $75.5 \pm 24.5$ & NA \\
\hline Total serum IgE $(\mathrm{IU} / \mathrm{mL})^{\mathrm{b}}$ & $196.8 \pm 227.9$ & $458.5 \pm 651.5$ & NA \\
\hline Eosinophil (cells $/ \mu \mathrm{L})^{\mathrm{c}}$ & $685.5 \pm 793.3$ & $321.0 \pm 326.6$ & NA \\
\hline
\end{tabular}

Table 1: Clinical and hematological characteristics of the study subjects $^{\mathrm{a}}$.
aData are presented as means \pm SD or numbers (\%).

$\mathrm{bP}<0.01$ for AERD patients vs. ATA patients by the Welch's t-test $\mathrm{cP}<0.01$ for AERD patients vs. ATA patients by the Welch's t-test

AERD: Aspirin-Exacerbated Respiratory Disease; ATA: AspirinTolerant Asthma; NC, Normal Controls; FEV1: Forced Expiratory Volume in One Second; IgE: Immunoglobulin E; NA: Not Applicable.

Table 2 indicates the frequencies of the SLC6A12 intron $2 \mathrm{~A}>\mathrm{T}$ and exon $4 \mathrm{~T}>\mathrm{C}$ genotypes and the minor alleles in each group. The genotype distribution fulfills the Hardy-Weinberg equilibrium in each group. The frequencies of the $\mathrm{T}$ minor allele of the intron $2 \mathrm{~A}>\mathrm{T}$ genotype in ATA patients (frequency of allele $[\mathrm{q}]=0.270$ ) and normal controls $(\mathrm{q}=0.215)$ were similar, whereas the frequency in AERD patients was increased $(q=0.333)$. The frequency of the $\mathrm{T}$ allele of the intron $2 \mathrm{~A}>\mathrm{T}$ genotype in AERD patients was significantly higher than that in normal controls $(\mathrm{P}=0.009)$. On the other hand, the frequencies of the $\mathrm{C}$ minor allele of the exon $4 \mathrm{~T}>\mathrm{C}$ genotype in ATA patients and normal controls were similar ( $\mathrm{q}=0.183$ in ATA patients and $\mathrm{q}=0.160$ in normal controls, respectively), whereas the frequency in AERD patients was increased $(\mathrm{q}=0.281)$. The frequency of the $\mathrm{C}$ variant allele of the exon $4 \mathrm{~T}>\mathrm{C}$ in AERD patients was significantly higher than that in ATA patients and normal controls $(\mathrm{P}=0.010$ in ATA patients and $\mathrm{P}=0.009$ in normal controls, respectively).

Minor alleles of each gene in patients with AERD were compared with that in patients with ATA and that in control subjects by means of the Chi-square test. Values in bold indicate significant P-value. AERD: Aspirin-Exacerbated Respiratory Disease; ATA: Aspirin-Tolerant Asthma; NC: Normal Controls; HWE: Hardy-Weinberg Equilibrium.

\begin{tabular}{|c|c|c|c|c|c|c|c|}
\hline \multirow{3}{*}{$\begin{array}{l}\text { SNP loci } \\
\text { Intron } 2 \mathrm{~A}>\mathrm{T}\end{array}$} & \multirow{2}{*}{\multicolumn{3}{|c|}{ Genotype, No. (\%) }} & \multirow{4}{*}{ Allele Frequency } & \multirow{2}{*}{\multicolumn{2}{|c|}{$\begin{array}{l}\text { Allele Frequency } \\
\text { P-value }\end{array}$}} & \multirow{4}{*}{$\begin{array}{l}\text { HWE } \\
\text { P-value }\end{array}$} \\
\hline & & & & & & & \\
\hline & AA & AT & TT & & & & \\
\hline Exon $4 \mathrm{~T}>\mathrm{C}$ & TT & TC & $\mathrm{CC}$ & & & & \\
\hline \multicolumn{4}{|l|}{ Intron $2 \mathrm{~A}>\mathrm{T}$} & \multicolumn{4}{|l|}{ T allele } \\
\hline AERD & $49(47.6 \%)$ & $40(38.8 \%)$ & $14(13.6 \%)$ & 0.333 & 0.099 & 0.099 & 0.216 \\
\hline ATA & $162(54.0 \%)$ & $114(38.0 \%)$ & $24(8.0 \%)$ & 0.27 & - & 0.123 & 0.553 \\
\hline NC & $63(63.0 \%)$ & $31(31.0 \%)$ & $6(6.0 \%)$ & 0.215 & 0.123 & - & 0.414 \\
\hline \multicolumn{4}{|l|}{ Exon $4 \mathrm{~T}>\mathrm{C}$} & \multicolumn{4}{|l|}{ C allele } \\
\hline AERD & 55 (53.4\%) & $41(39.8 \%)$ & $7(6.8 \%)$ & 0.281 & 0.010 & 0.009 & 0.863 \\
\hline ATA & $200(66.7 \%)$ & $90(30.0 \%)$ & $10(3.3 \%)$ & 0.183 & - & 0.455 & 0.974 \\
\hline NC & $72(72.0 \%)$ & $24(24.0 \%)$ & $4(4.0 \%)$ & 0.16 & 0.455 & - & 0.284 \\
\hline
\end{tabular}

Table 2: Genotype and allele frequencies of the intron $2 \mathrm{~A}>\mathrm{T}$ and exon $4 \mathrm{~T}>\mathrm{C}$ gene in each group.

Table 3 - (A) presents the results of multivariable logistic regression analysis of the SLC6A12 intron $2 \mathrm{~A}>\mathrm{T}$ and exon $4 \mathrm{~T}>\mathrm{C}$ genotypes, controlling for age and gender in AERD patients compared with those with ATA. Frequencies in the combined homozygous TT and heterozygous AT genotype group of SLC6A12 intron $2 \mathrm{~A}>\mathrm{T}$ were not different from those of homozygous AA genotype in patients with AERD compared with those with ATA $(\mathrm{P}=0.276)$. The odds ratio $(\mathrm{OR})$ of patients with AERD compared with those with ATA patients associated with combined homozygous TT and heterozygous AT genotype group of SLC6A12 intron $2 \mathrm{~A}>\mathrm{T}$ to those with homogenous 
AA genotype was 1.285 (95\% confidence interval $(\mathrm{CI})=0.818-2.016$ ). On the other hand, the frequencies in the combined homozygous CC and heterozygous TC genotype group of SLC6A12 exon 4 T>C were significantly higher than those of the homozygous TT genotype in patients with AERD compared with those with ATA ( $\mathrm{P}=0.021)$, and the OR of patients with AERD compared with those with ATA patients associated with combined homozygous CC and heterozygous CT genotype group to those with homozygous TT genotype was 1.724 (95 $\% \mathrm{CI}=1.087-2.732$ ).

\begin{tabular}{|l|l|}
\hline \multicolumn{2}{|l|}{$(\mathbf{A})$} \\
\hline SNPs loci & OR $(95 \% \mathrm{Cl})$, P-value \\
\hline Genotype & \\
\hline Intron 2 A>T & 1 \\
\hline AA & $1.285(0.818-2.016), 0.276$ \\
\hline AT/TT & \\
\hline Exon 4 T>C & 1 \\
\hline TT & $1.724(1.087-2.732), \mathbf{0 . 0 2 1}$ \\
\hline TC/CC & \\
\hline
\end{tabular}

\section{(B)}

\begin{tabular}{|l|l|l|}
\hline SNPs loci & Male & Female \\
\hline Genotype & OR (95\%Cl), P-value & OR $(95 \% \mathrm{Cl})$, P-value \\
\hline Intron 2 A $>$ T
\end{tabular}

\begin{tabular}{|l|l|l|}
\hline \multirow{2}{*}{$\begin{array}{l}\text { AA } \\
\text { AT/TT }\end{array}$} & 1 & 1 \\
\cline { 2 - 3 } & $1.315(0.564-3.070), 0.526$ & $1.280(0.751-2.181), 0.365$ \\
\hline
\end{tabular}

Exon $4 \mathrm{~T}>\mathrm{C}$

\begin{tabular}{l|l|l|}
\hline \multirow{2}{*}{$\mathrm{TT}$} & 1 & 1 \\
\cline { 2 - 3 } $\mathrm{TC} / \mathrm{CC}$ & $3.177(1.311-7.699), \mathbf{0 . 0 1 0}$ & $1.368(0.792-2.363), 0.261$
\end{tabular}

Table 3: Multivariable logistic regression analysis (A) and the subgroup analysis with gender (B) of genotype of the intron $2 \mathrm{~A}>\mathrm{T}$ and exon 4 $\mathrm{T}>\mathrm{C}$ gene in Japanese patients with aspirin-exacerbated respiratory disease compared with those with aspirin-tolerant asthma ${ }^{\mathrm{a}}$.

${ }^{a}$ Multivarible logistic regression analysis was applied for age and gender (A) and age (B) as covariables. Values in bold indicate significant P-Value. SNP: Single Nucleotide polymorphism; OR: Odds Ratio; CI: Confidence Interval.

Subgroup analyses with gender of the SLC6A12 genotypes showed the positive association between asthma phenotype and the SLC6A12 exon $4 \mathrm{~T}>\mathrm{C}$ genotype in male patients, but not in female patients as shown in Table 3 - (B). Namely, in male patients with AERD the frequencies of the combined homozygous CC and heterozygous TC genotype group were higher than those of the homozygous TT genotype compared with male ATA patients $(\mathrm{P}<0.010, \mathrm{OR}=3.177,95 \%$ $\mathrm{CI}=1.311-7.699)$. On the other hand, no positive association was present between asthma phenotype and the SLC6A12 intron $2 \mathrm{~A}>\mathrm{T}$ genotype both in male $(\mathrm{P}=0.526 ; \mathrm{OR}=1.315,95 \% \mathrm{CI}=0.564-3.070)$ and in female $(\mathrm{P}=0.365, \mathrm{OR}=1.280,95 \% \mathrm{CI}=0.751-2.181)$.
Comparison of the clinical characteristics in AERD patients according to the SLC6A12 gene polymorphisms revealed that FEV1 in patients with the combined homozygous CC and heterozygous TC genotype group of the SLC6A12 exon $4 \mathrm{~T}>\mathrm{C}$ showed significantly lower than that in the patients with the homozygous TT genotype $(\mathrm{P}=0.039)$. The levels of total serum IgE and peripheral blood total eosinophil count were not different between the polymorphisms in each gene (Table 4).

\begin{tabular}{|c|c|c|c|}
\hline SNPs loci & FEV1 & Total IgE & Eosinopil \\
\hline Genotype & (\% predicted) & $(\mathrm{IU} / \mathrm{mL})$ & (cells/ $/ \mathrm{LL}$ ) \\
\hline \multicolumn{4}{|l|}{ Intron $2 \mathrm{~A}>\mathrm{T}$} \\
\hline AA & $74.1 \pm 11.9$ & $214.9 \pm 208.8$ & $698.1 \pm 957.2$ \\
\hline AT/TT & $73.7 \pm 11.2$ & $144.9 \pm 130.7$ & $672.2 \pm 585.9$ \\
\hline$P$-value & 0.875 & 0.141 & 0.877 \\
\hline \multicolumn{4}{|l|}{ Exon $4 \mathrm{~T}>\mathrm{C}$} \\
\hline TT & $76.1 \pm 11.3$ & $165.7 \pm 155.0$ & $604.9 \pm 783.7$ \\
\hline $\mathrm{TC} / \mathrm{CC}$ & $71.4 \pm 11.0$ & $234.3 \pm 290.7$ & $777.2 \pm 803.3$ \\
\hline P-value & 0.039 & 0.19 & 0.301 \\
\hline
\end{tabular}

Table 4: Comparison of the clinical characteristics according to intron $2 \mathrm{~A}>\mathrm{T}$ and exon $4 \mathrm{~T}>\mathrm{C}$ gene polymorphisms in Japanese patients with aspirin-exacerbated respiratory diseasea.

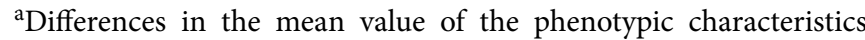
within the patients were compared by t-test. Values in bold indicate significant P-Value. FEV1: Forced Expiratory Volume in One Second; IgE: Immunoglobulin E.

\section{Discussion}

To elucidate any genetic influence of the GABAergic system in AERD occurrence, we investigated the genetic association of SLC6A12 with AERD in a Japanese population. In this study, the patients with AERD and those with ATA revealed comparable distribution of age and gender, and then we assessed the clinical and hematological characteristics of the subjects. All patients were in a stable clinical condition, and there was no significant difference between AERD patients and ATA patients in terms of age, gender and FEV1 (\% predicted). The levels of total serum IgE in AERD patients were lower than those in ATA patients $(\mathrm{P}<0.001)$. AERD patients had a higher peripheral blood total eosinophil count compared with ATA patients $(\mathrm{P}<0.001)$. Our results correspond to the reports that AERD is associated with eosinophilia and less atopic tendency than ATA $[1,25]$.

Next, we investigated the frequencies of the SLC6A12 intron $2 \mathrm{~A}>\mathrm{T}$ and SLC6A12 exon $4 \mathrm{~T}>\mathrm{C}$ genotype in three groups (AERD patients, ATA patients and normal controls). The genotype distributions fulfill the Hardy-Weinberg equilibrium in each group. The frequencies of the $\mathrm{T}$ minor allele of the intron $2 \mathrm{~A}>\mathrm{T}$ genotype in AERD patients was significantly higher than that in normal controls $(\mathrm{P}=0.009)$. The frequency of the $\mathrm{C}$ variant allele of the exon $4 \mathrm{~T}>\mathrm{C}$ in AERD patients was significantly higher than that in ATA patients and normal controls $(\mathrm{P}=0.010$ in ATA patients and $\mathrm{P}=0.009$ in normal controls, respectively). Frequencies in the combined homozygous $\mathrm{TT}$ and heterozygous AT genotype group of SLC6A12 intron $2 \mathrm{~A}>\mathrm{T}$ were not 
different from those of homozygous AA genotype in patients with AERD compared with those with ATA. On the other hand, the frequencies of the combined homozygous CC/heterozygous TC genotype group of SLC6A12 exon $4 \mathrm{~T}>\mathrm{C}$ were significantly higher than those of the homozygous TT genotype in patients with AERD compared with those with ATA $(\mathrm{P}=0.021)$.

Subgroup analyses with gender of the SLC6A12 genotype showed the positive association between asthma phenotype and the SLC6A12 exon $4 \mathrm{~T}>\mathrm{C}$ genotype, but not the SLC6A12 intron $2 \mathrm{~A}>\mathrm{T}$ genotype. Namely, in male patients, but not in female patients, the frequencies of the combined homozygous CC and heterozygous TC genotype group of SLC6A12 exon $4 \mathrm{~T}>\mathrm{C}$ were higher than those of the homozygous TT genotype compared with male ATA patients $(\mathrm{P}<0.010)$. It has been well known since the late 1960's that AERD is more commonly found in female than in males [26]. At present, we have no evidence to explain the fact that there was a statistical significance in SLC6A12 exon $4 \mathrm{~T}>\mathrm{C}$ polymorphisms in male patients with AERD, but not in females. However, there are many SNPs in same gene, and those potentially may affect the susceptibility of AERD, and therefore other factors conferring the susceptibility of AERD remains to be identified.

Comparison of the clinical characteristics in AERD patients according to the SLC6A12 gene polymorphisms revealed that FEV1 in patients with the combined homozygous CC and heterozygous TC genotype group of the SLC6A12 exon $4 \mathrm{~T}>\mathrm{C}$ showed significantly lower than that in the patients with the homozygous TT genotype $(\mathrm{P}=0.039)$, suggesting the SLC6A12 exon $4 \mathrm{~T}>\mathrm{C}$ genotype may be related to one of the determinant factors for the severity of AERD.

Our results may correspond to the paper from Korea [22], which reported the minor allele frequencies of two polymorphisms (rs499368 and rs557881) were significantly higher in AERD than in ATA, and the translation of the amino acid change from $\mathrm{T}$ (cysteine) to $\mathrm{C}$ (arginine) in rs557881 polymorphism. Therefore, taking our present data into account, we may suggest these variants might be involved in the risk of aspirin hypersensitivity among asthmatics. As we have no more evidence, this work did not describe the mechanism linking the SLC6A12 exon $4 \mathrm{~T}>\mathrm{C}$ genotype and the severity of AERD. However we may propose some possibilities. Namely, cysteine is an amino acid with a non-polar side chain that contains uncharged functional groups as physiological $\mathrm{pH}$ and groups incapable of participating in hydrogen bonding, whereas arginine is an amino acid with a polar side chain that contains groups that are either charged at physiological $\mathrm{pH}$ or groups that are able to participate in hydrogen bonding. So, modification of cysteine and replacing the guanidine group with a urea linkage in the side chain of arginine could be a risk factor for asthma, including aspirin hypersensitivity. Interestingly, it has been reported that the extra neuronal GABAergic system might to be implicated in the mechanisms of AERD [21].

The present study has certain limitations. First, the number of the subjects was limited. The larger population, the more one can generalize the results. Secondarily, the diagnosis of AERD was made on the basis of either a positive result on lysine-aspirin challenge test [4] or an apparent history of more than one self-reported episode of bronchial response to aspirin or NSAID ingestion. The clinical history indicated drug hypersensitivity appeared less than 24 hours between administration of the suspected drug and the onset of reactive symptoms as recommended by European Network for Drug Allergy [27]. Although placebo-controlled oral challenge tests are considered the best, the suspected drugs were not applied to the subjects in this study because of patients' refusal and our safety policy of inpatient provocations only [24]. ATA was defined as bronchial asthma with no history of NSAID-induced asthma attack. Ideally everyone in the study should have had the challenge test to be certain about aspirin intolerance. However, a good number of the patients with AERD were recruited from the outpatient clinics of the experienced pulmonologists in Japan. Interestingly, aspirin has been shown to be involved in the detoxification of GABAlytic picrotoxin, an antagonist for GABA type A receptor [28]. The inhibition of picrptoxin by aspirin restores GABA activity, suggesting such interactions with aspirin might be present in pathobiology of AERD. Further studies are required including replication studies in another population, and it is obvious that generalizing is necessary for forming coherent interpretations in different situations.

In conclusion, we sought to partly replicate the association previously described between SLC6A12 gene and AERD patients among Korean population [22], and this is the first Japanese study to analyze the SLC6A12 intron $2 \mathrm{~A}>\mathrm{T}$ and SLC6A12 exon $4 \mathrm{~T}>\mathrm{C}$ genotype polymorphisms in patients with AERD. Although our results correspond to those in a Korean population, our studies were based on small-sized samples, and further validation studies in independent population are thus required.

\section{Ethical disclosures}

Institutional ethics committee approved this study and written informed consent from each individual was obtained before the study.

\section{Authors' Contributions}

MK designed the research study, and MK along with TY, SH collected and analyzed data. MK, YS, TY, SH and ES drafted the manuscript. All authors read and approved the final manuscript.

\section{References}

1. Szczeklik A, Nizankowska E, Duplaga M (2000) Natural history of aspirin-induced asthma. AIANE Investigators. European Network on Aspirin-Induced Asthma. Eur Respir J 16: 432-436.

2. Higashi N, Mita H, Ono E, Fukutomi Y, Yamaguchi H, et al. (2010) Profile of eicosanoid generation in aspirin-intolerant asthma and anaphylaxis assessed by new biomarkers. J Allergy Clin Immunol 125: 1084-1091.

3. Sanak M, Simon HU, Szczeklik A (1997) Leukotriene C4 synthase promoter polymorphism and risk of aspirin-induced asthma. Lancet 350: 1599-1600.

4. Kawagishi Y, Mita H, Taniguchi M, Maruyama M, Oosaki R, et al. (2002) Leukotriene C4 synthase promoter polymorphism in Japanese patients with aspirin-induced asthma. J Allergy Clin Immunol 109: 936-942.

5. Kim SH, Bae JS, Suh CH, Nahm DH, Holloway JW, et al. (2005) Polymorphism of tandem repeat in promoter of 5-lipoxygenase in ASAintolerant asthma: a positive association with airway hyperresponsiveness. Allergy 60: 760-765.

6. Kim SH, Oh JM, Kim YS, Palmer LJ, Suh CH, et al. (2006) Cysteinyl leukotriene receptor 1 promoter polymorphism is associated with aspirin-intolerant asthma in males. Clin Exp Allergy 36: 433-439.

7. Van Sambeek R, Stevenson DD, Baldasaro M, Lam BK, Zhao J, et al. (2000) 5' flanking region polymorphism of the gene encoding leukotriene C4 synthase does not correlate with the aspirin-intolerant asthma phenotype in the United States. J Allergy Clin Immunol 106: 72-76.

8. Choi JH, Park HS, Oh HB, Lee JH, Suh YJ, et al. (2004) Leukotrienerelated gene polymorphisms in ASA-intolerant asthma: an association with a haplotype of 5-lipoxygenase. Hum Genet 114: 337-344. 
Citation: Kurosawa M, Sutoh Y, Yukawa T, Hozawa S, Sutoh E (2015) Solute Carrier Family 6 Member 12 Gene Polymorphisms in Japanese Patients with Aspirin-Exacerbated Respiratory Disease. J Allergy Ther 6: 220. doi:10.4172/2155-6121.1000220

Page 6 of 6

9. Kohyama K, Abe S, Kodaira K, Yukawa T, Hozawa S, et al. (2011) Arg16Gly $\hat{I}^{2} 2$-adrenergic receptor gene polymorphism in Japanese patients with aspirin-exacerbated respiratory disease. Int Arch Allergy Immunol 156: 405-411.

10. Kohyama K, Abe S, Kodaira K, Yukawa T, Hozawa S, et al. (2011) IL-13 and IL-17A gene polymorphisms in Japanese patients with aspirinexacerbated respiratory disease. Ann Allergy Asthma Immunol 107: $510-516$.

11. Kohyama K, Abe S, Kodaira K, Yukawa T, Hozawa S, et al. (2011) Polymorphisms of the CYP2C19 gene in Japanese patients with aspirinexacerbated respiratory disease. J Allergy Clin Immunol 128: 1117-1120.

12. Kohyama K, Hashimoto M, Abe S, Kodaira K, Yukawa T, et al. (2012) Thromboxane A2 receptor $+795 \mathrm{~T}>\mathrm{C}$ and chemoattractant receptorhomologous molecule expressed on Th2 cells $-466 \mathrm{~T}>\mathrm{C}$ gene polymorphisms in patients with aspirin-exacerbated respiratory disease. Mol Med Rep 5: 477-482.

13. Kikuchi K, Abe S, Kodaira K, Yukawa T, Hozawa S, et al. (2013) Hea shock protein 70 gene polymorphisms in Japanese patients with aspirinexacerbated respiratory disease. J Investig Med 61: 708-714.

14. Kurosawa M, Yukawa T, Hozawa S, Mochizuki H (2015) Recent advance in investigation of gene polymorphisms in Japanese patients with aspirinexacerbated respiratory disease. Allergol Immunopathol (Madr) 43: 92-100.

15. Xiang YY, Wang S, Liu M, Hirota JA, Li J, et al. (2007) A GABAergic system in airway epithelium is essential for mucus overproduction in asthma. Nat Med 13: 862-867.

16. Corry DB, Kheradmand F (2007) A new link to airway obstruction in asthma. Nat Med 13: 777-778.

17. Lu WY, Inman MD (2009) Gamma-aminobutyric acid nurtures allergic asthma. See comment inPubMed Commons below Clin Exp Allergy 39 956-961.

18. Rasola A, Galietta LJ, Barone V, Romeo G, Bagnasco S (1995) Molecular cloning and functional characterization of a GABA/betaine transporter from human kidney. FEBS Lett 373: 229-233.
19. Matskevitch I, Wagner CA, Stegen C, Bröer S, Noll B, et al. (1999) Functional characterization of the Betaine/gamma-aminobutyric acid transporter BGT-1 expressed in Xenopus oocytes. J Biol Chem 274: 16709-16716.

20. Borden LA (1996) GABA transporter heterogeneity: pharmacology and cellular localization. Neurochem Int 29: 335-356.

21. Warner SM, Knight DA (2008) Airway modeling and remodeling in the pathogenesis of asthma. Curr Opin Allergy Clin Immunol 8: 44-48.

22. Pasaje CF, Kim JH, Park BL, Cheong HS, Chun JY, et al. (2010) Association of SLC6A12 variants with aspirin-intolerant asthma in a Korean population. Ann Hum Genet 74: 326-334.

23. Global Initiative for Asthma (GINA), National Heart, Lung and Blood Institute (NHLBI) Global strategy for asthma management and prevention. Bethesda (MD) (2006) Global Initiative for Asthma (GINA), National Health, National Heart, Lung and Blood Institute (NHLBI).

24. Buhl T, Meynberg HC, Kaune KM, Hünecke P, Schön MP, et al. (2011) Long-term follow-up of patients with hypersensitivity to nonsteroidal anti-inflammatory drugs reveals shortcomings in compliance and care. J Allergy Clin Immunol 127: 284-285.

25. Sampson AP, Cowburn AS, Sladek K, Adamek L, Nizankowska E, et al. (1997) Profound overexpression of leukotriene C4 synthase in bronchial biopsies from aspirin-intolerant asthmatic patients. Int Arch Allergy Immunol 113: 355-357.

26. Samter M, Beers RF Jr (1968) Intolerance to aspirin. Clinical studies and consideration of its pathogenesis. Ann Intern Med 68: 975-983.

27. Aberer W, Bircher A, Romano A, Blanca M, Campi P, et al. (2003) Drug provocation testing in the diagnosis of drug hypersensitivity reactions: general considerations. Allergy 58: 854-863.

28. Golovko A, Sofronov GA, Kliuntina TV (1995) [The effect of salicylates on the toxicity of GABAlytics for mice]. Biull Eksp Biol Med 119: 619-620. 